\title{
The Level of High-Order Thinking and Its Relation to Quality of Life among Students at Ajloun University College
}

\author{
Wail Minwer Al Rabadi ${ }^{1} \&$ Rifqa Khleif Salem ${ }^{1}$ \\ ${ }^{1}$ Ajloun University College, Al Balqa Applied University, Jordan \\ Correspondence: Wail Minwer Al Rabadi, Ajloun University College, Al Balqa Applied University, Jordan. \\ E-mail: wail_rabadi@yahoo.com
}

Received: October 2, 2017

Accepted: January 30, $2018 \quad$ Online Published: May 17, 2018

doi:10.5539/ies.v11n6p8

URL: https://doi.org/10.5539/ies.v11n6p8

\begin{abstract}
The study was designed to identify the effect of high-order thinking on the quality of life among Ajloun University students. The study used the associative method. The randomly selected sample consisted of 147 students from Ajloun University College. The study used two tools: The two measures were applied to the sample of the current study after extracting the psychometric properties of the two scales in terms of validity and reliability.

The results indicated that the high-order thinking among the students was moderate. The students also achieved a medium degree according to the quality of life scale. There was a statistically significant correlation between both the high-order thinking and the quality of life. There were statistically significant differences in quality of life and the level of high-order thinking due to gender variable in favor of males and academic specialization in favor of students of scientific colleges, the study recommended the need for further research and studies on the relationship between quality of life and other variables such as self-efficacy, self-learning, and other variables, and to train students in skills that raise their high-order thinking skills because of their close relationship with quality of life and training programs and semi-empirical studies to improve students' perception of level of life and its quality and satisfaction.
\end{abstract}

Keywords: high-order thinking, quality of life, Ajloun University College

\section{Introduction}

It is the man who causes suffering in this world. He is hurt in his suffering but he learns and thus reduces the pain that raises the quality of his life through his thinking and learning. A normal personality is characterized by its positive attributes. Happiness, self-satisfaction and others, and the ability to express oneself to provide and help the individual to grow and develop, as these features are the outcome of the effort of the individual in his quest to benefit from the potential and abilities and work on their development to achieve psychological and social compatibility, especially in light of the conditions of contemporary life described as productive conditions of all forms of distress and emotional distress. These circumstances require balanced thinking that can save the individual from surrounding negative inhibitions and stimuli.

Thinking is one of the concepts that have received the attention of the workers in the field of psychology, where Abu Hatab and Othman claimed that the psychology of thinking represent a special status in contemporary psychology, because of the increased interest of psychology in cognitive processes, and it can be said: this age is an age of interest in the psychology of thinking. Relating the types of thinking Paul referred to three types of thinking: casual thinking, which is a simple thinking related to short-term memory, and guided thinking, which helps to learn the curriculum and solve problems according to a specific goal, scientific thinking with scientific methodology, and has several patterns: Critical thinking, logical thinking, creative thinking, reflective thinking, intuitional thinking, analytical thinking, contemplative thinking). Which fall within the high-order thinking and through the previous types, it is clear that higher-order thinking is a pattern of scientific thinking (Abu Hatab \& Othman, 1988).

High-order thinking is one of the most important educational dimensions that educators have begun to consider in recent years as important keys to achieving the educational goals of the learning process. This is to ensure that the cognitive development that motivates the individual to use his or her maximum mental abilities to achieve success and proper adjustment in learning or public life (Otoum \& Jarrah, 2015). The high-order thinking is also 
considered a thinking pattern, which requires a special mental effort, the ability to tolerate doubt and mystery, independence in mental trials, expansion of the limits of knowledge in what is being discovered, and why they occur in different ways (Lipman, 1991). Based on its impact on behavior in which the quality of life considered a part of it, which has become a subject of importance in psychology because of its impact on human life, where the concept of quality of life was adopted in various disciplines, theory and practice, psychology had the first role in disclosure on the variables that affect the quality of life and help to understand it, due to the quality of life as an expression of self-perception, life for the human being what he can perceive.

Quality of life has been referred to as a set of integrated, planned and ongoing processes aimed at improving the various aspects that affect the employees' careers and personal lives, which contributes to the achievement of the strategic objectives of the organization, its employees and its clients (El-Rab, 2008). The concept of quality of life is a multidimensional and relative concept differs from person to person from both theoretical and practical perspectives according to the criteria that individuals adopt to evaluate life and reality which are often influenced by many factors that influence the determination of quality of life components, such as the ability to think, to make decisions, to be able to control, to manage the surrounding conditions, physical and psychological health, economic and religious conditions, cultural and civilizational values, education and recreation, Human rights and happiness, through which individuals identify important things that bring happiness to life.

Because thinking is a form of human behavior, which is one of the highest levels of mental activity, which is a form of quality of life, and is one of the most important characteristics that characterize the human than other creatures, and this means that the quality of life of the individual is linked to the level he reached in satisfying the various psychological needs, health, creativity and the ability to practice thinking, and the different activities as provided by the various social institutions and organizations of the possibilities according to the capabilities that he possesses and which tries to exploit this potential to satisfy those needs and the sense of quality of life, according to the time and how these needs were practiced (Y. Qatami, N. Qatami, \& Hamdi, 2010).

\subsection{Problem of the Study}

The quality of life is an important part of the promotion of health, social and educational organizations, which contributes to the creation of positive results for practitioners of human behavior in various places (Burtson \& Stichler, 2010). The development of quality-of-life methods in these institutions has become a necessity for its positive impact in achieving the competitive advantage of these institutions and reaches the highest levels of giving (Northouse, 2013).

As the quality of life is linked to human and social activity, which does not depend on the boundaries of the personal sphere, it extends beyond the various human and personal spheres, which can affect people's lives and abilities, including work, thinking and the ability to give with a negative or positive effects. Consequently, educators aim to investigate problems that hinder or affect the quality of life of individuals, with a view to identifying and working to address them to reach the acceptable level of quality of life.

Due to the importance of the subject of thinking and its impact on the behavior of individuals and their quality of life and the practice of various daily life activities, and all the above it is clear to the researcher the need and importance of revealing the level of thinking skills and quality of life of individuals and their relationship, Which came through the work of the researcher in the academic center and what is observed continuously that there is a kind of resentment and permanent fatigue of life in many aspects from the students and despair and the ambiguity of the future and the state of indifference that surrounds them, and stay in a specific framework of thinking, the faculty members' perception is based on the researcher's convictions about the students' reality, which takes the negative attitude, which sometimes shows the students' inability to perform on the achievement tests and their refusal to accept the types of questions that involve the higher thinking skills as they affect their academic achievement, as well as the limited thinking they practice in their dialogue and its responses to exam questions. The problem of the study is to answer the following questions:

1) What is the level of high-order thinking and quality of life among Ajloun University college students?

2) Is there a statistically significant correlation relationship at the level of significance $(\alpha=0.05)$ between the high-order thinking and the quality of life among the students of Ajloun University College?

3) Are there statistically significant differences at the level of $(\alpha=0.05)$ in the high-order thinking and quality of life among Ajloun University college students according to gender and specialization?

\subsection{The Importance of the Study}

The importance of the current research is to shed light on an important and vital topic for the individuals in the societies in which we live and which the students belong to in Jordanian universities, namely the relationship 
between high-order thinking and quality of life and the disclosure of the factors that may be the reason for the existence or absence of this relationship in addition to the importance of the quality of the variables that have been linked together, which to the knowledge of the researcher has not been studied together before, and that is important in the social and academic aspects of students.

The present study is of particular importance for several considerations, including:

1) It is the first study considering the relationship between one of the positive concepts in the human personality which is the high-order thinking and the quality of life so as to provide educational and psychological literature for scholars.

2) Reveals levels of high-order thinking, quality of life and their relation to gender and type of specialization for students.

3) Scarcity of studies that dealt with the two variables together.

4) Investigate the extent to which there is a correlation between high-order thinking and quality of life among students at Ajloun University College.

5) Investigate the differences in the level of high-order thinking and quality of life of Ajloun University students according to gender and academic specialization variables.

\subsection{Objectives and Justifications of the Study}

The study aims to:

1) Investigating the existence of statistically significant correlation between high-order thinking and quality of life among students at Ajloun University College.

2) Investigating the existence of statistically significant differences among students at Ajloun University College on the high-order thinking scale due to the gender variable or specialization studied by the student.

3) Investigating the existence of statistically significant differences between the students of Ajloun University College on the quality of life scale due to gender, experience or interaction between them.

\subsection{Conceptual and Procedural Definitions}

High-order thinking: Newman (1991) defines it as the ability to use a wide range of mental processes, which occurs when the learner interprets and analyzes information to answer a question or solve a problem that can not be solved through the routine use of information previously learned, it includes, critical thinking, creative thinking, explanatory, and transcendental and reflective.

It is defined procedurally in this study as the degree to which the student obtained on the high-order thinking scale designed specifically for this study, which was reconstructed by the researcher.

The quality of life: identified by Ryff et al. (2006) as a positive sense of well-being, which is monitored by behavioral indicators of high levels of satisfaction with one's self and life in general, and its continuous pursuit of valued personal goals of value and meaning to it, the course of his life, and his establishment and continuation of positive social relations with others. The quality of psychological life is linked to the general sense of happiness, tranquility and psychological tranquility.

It is defined procedurally as a set of observable indicators and direct measurement, which is the degree to which the student obtained according to the quality of life criterion.

\subsection{The Limits of the Study}

1) Human Limitations: The study was limited to students of Ajloun University College.

2) Spatial boundaries: The study was applied to the students of Ajloun University College.

3) Time Limitations: The study was conducted during the first semester 2016-2017

4) Objective limitations: The current study is determined by its tools and the statistical methods used.

\section{Previous Studies}

The concepts of high-order thinking and quality of life are concepts that have received the attention of the psychological and educational sector because of their reflection on the personality of man and his development. However, the study of the two concepts together is one of the very rare studies (within the limits of the researcher's knowledge). A number of studies related to the variables of each of them, including: 


\subsection{Studies Relating the Quality of Life}

Shek (1993) examined the relationship between the goal of life as a dimension of quality of life and psychological happiness. The study sample consisted of 500 male and female students. The study found a positive relationship between quality of life and psychological happiness among university students.

The study of (Al-Adely, 2006) was designed to identify the extent of students' sense of quality of life at the Faculty of Education in Al-Rastaq, and its relation with some variables (gender, and academic specialization). The sample consisted of (51) male students and (147) female students, the results indicated that the average grade of male and female members of the sample is higher than the theoretical average of the scale that reflects a high level of quality of life. In addition, there are statistically significant differences between the average performances of the students on the quality of life standard according to the specialization.

The study of Naesa (2012) aimed at investigating the quality of life of the students of the University of Damascus and Teshreen by the variables of the country (governorate), gender (male, female) and specialization (theoretical sciences, applied sciences), the quality of life scale for university students was used by Minsi and Kadhim (2006), the sample of the study consisted of (360) students among which (180) from Damascus University and (180) from Tishreen University, where the results indicated the low quality of life among university students and the joint effect of the three demographic variables on the quality of life and the absence of statistical differences between males and females in quality of life.

The study of Najjar and Tallae (2015) was designed to identify the level of the relationship between positive thinking and its relation to the quality of life of civil society employees in Gaza governorate. The descriptive method was used. The study sample consisted of civil society employees in Gaza Governorate. The results indicated that there is a statistically significant relationship between positive thinking and quality of life. There are statistically significant differences in the measures of positive thinking and quality of life due to the gender variable in favor of males.

Al-Shanti's (2016) study aimed to define the level of quality of the career life and the degree of transformational driving practice in the Palestinian Ministry of Health in the Gaza Strip, as well as the impact of transformational leadership in its four dimensions on the quality of the career life, as well as the effect of procedural justice as an intermediate variable in the relationship between transformational leadership and quality of career life. In order to achieve the objectives of the research, the survey tool was developed based on the previous studies. The sample included 370 employees in the Gaza Strip. The results showed that the quality of life was average among working individuals and that transformational leadership directly affects the quality of life.

\subsection{Studies Relating the High-Order Thinking}

The study of Ibrahim (2012) aims to identify the habits of the mind, the high-order thinking, the self-efficacy, and the order of the habits and mind of the mind of students of the faculties of education, and knowing the difference in the level of habits of mind and high-order thinking and self-efficacy among students of faculties of education depending on the variables of gender, specialization and stage. Three tools were used: the measure of the habits of the mind and the test of high-level thinking, the measure of self-efficacy. The three measures were applied to a sample of 400 students who were randomly selected. The most prominent results have been as follows: Individuals in the study sample possess relatively high-order thinking. The habits of the mind are not affected by gender, specialization, or stage, while there was a significant effect on gender, specialization and stage in the high-order thinking in favor of females, human specialization and the first stage, respectively.

The study of Abdul Wahid (2012) aims to identify the effectiveness of teaching with high-order thinking skills according to the method of teaching thinking within the cognitive content of the biology of achievement and the adequacy of cognitive representation and the development of critical thinking among the fourth grade students, and dealt with the following thinking skills: organizing information, Open-ended problem solving, data analysis and modeling, ability to formulate predictions, application, installation, evaluation. An objective sample was selected from Al-Rabab prep school for girls in Diwaniyah city, consisting of 63 students divided into two groups, experimental and control. The results indicated that there were statistically significant differences in favor of the experimental group in the achievement of the biology and intermediate level, as well as the existence of statistically significant differences in favor of the experimental group in the measurement of the adequacy of the cognitive representation and above the medium, and the existence of statistically significant differences in favor of the experimental group in the development of critical thinking and to a medium extent.

The study of Nawab and Hussein (2012) defined the level of the habits of the mind and the high-order thinking and their relation to the self-efficacy of the students of the Faculty of Education, according to gender variable, 
specialization and stage in the students of the Faculty of Education, and was used the measure of habits of mind, and the test of high-order thinking (creative and critical), the study sample consisted of 400 students from the Faculty of Education, where the results showed that the members of the sample have high-order thinking with a low rate, and that high-order thinking is affected by gender and that females have high-order thinking higher than males, And that the students of the humanitarian colleges have high-order thinking higher than the scientific colleges, and the first year students enjoy high-order thinking is greater than other years. The relationship of high-order thinking to self-efficacy is weak.

The study of Al-Shuraideh and Bishara (2010) aimed to reveal the composite thinking and its relation to gender, the cumulative rate and the academic specialization of the students of Al-Hussein Bin Talal University. The sample consisted of (332) students. The results indicated that the creative thinking style is the most common, there is a statistically significant effect on the variables of gender, specialization or level of study in the ability to composite thinking, and there is a statistically significant effect of the variable on composite thinking and for the benefit of students from an acceptable level.

The researcher benefited from the previous studies in the selection of the sample of the study which showed that the studies did not apply any study related to the subject on that sample, in addition to that helped the researcher in formulating the problem of study and emphasize its importance and to benefit from the discussion of the results of the study and compare with some of the findings that the researcher reached in addition to the introduction to some references that helped the researcher in preparing for the research. The present study was distinguished from other studies. The first study was considered at the level of the Arab world in general and Jordan in particular (within the limits of the researcher's knowledge), which dealt with the two variables together.

\section{Method and Procedures}

\subsection{Study Approach}

The present study used the descriptive correlative approach to suit the objectives, nature and questions of the study by applying the criteria of the study, the quality of life criterion and the high-order thinking scale to identify the results of each scale and the relationship between them.

\subsection{Population of the Study}

The study population composed of students from Ajloun University College.

\subsection{The Study Sample}

A random sample of 147 male and female students ( 68 males, 79 females) was selected from the students of Ajloun University College. These students were selected from the specializations (Psychological Counseling and Special Education) from the Department of Humanities and Computer and Mathematics from the Scientific Department, as shown in the following table.

Table 1. Distribution of the study sample according to its variables

\begin{tabular}{ccccc}
\hline $\mathrm{N}$ & Variable & Gender & $\mathrm{N}$ & Ratio \\
\hline 1 & & Males & 68 & $46 \%$ \\
2 & Gender & Females & 79 & $54 \%$ \\
3 & & Total & 147 & $100 \%$ \\
1 & & scientific & 59 & $40 \%$ \\
2 & Specialization & Humanitarian & 88 & $60 \%$ \\
3 & & Total & 147 & $100 \%$ \\
\hline
\end{tabular}

\subsection{Study Tools}

Two tools were used to achieve the objectives of the study:

\subsubsection{First tool: Quality of Life Scale}

The scale developed by Shekhi (2014), which measures the quality of life, the scale consisted of 30 paragraphs and includes six dimensions: (feelings of quality of life, daily activities, different aspects of life, number of past experiences, mobility and personal beliefs). Each dimension includes five paragraphs. Where the student responds according to the gradual Likert pentacle: "Strongly agree, agree, Neutral, Disagree, Strongly Disagree."

Validity of Quality of Life Scale 
The test was presented to eleven arbitrators to judge the suitability of its paragraphs to the students, the clarity of its language, the effectiveness of its substitutions, the suitability of its number, and the extent to which it represent the dimensions of the quality of life scale. The correlation coefficients of the quality-of-life scale were calculated by the total score of the scale as shown in Table 2.

Table 2. Correlation coefficients of the quality of life scale measures with the total grade of the scale

\begin{tabular}{|c|c|c|c|c|c|c|c|c|c|}
\hline 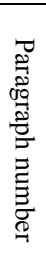 & 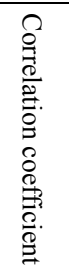 & 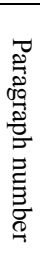 & 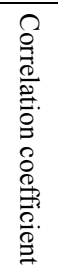 & 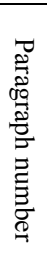 & 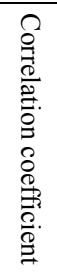 & 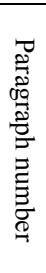 & 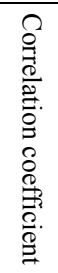 & 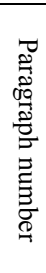 & 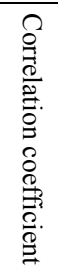 \\
\hline 1 & .799 & 7 & .713 & 13 & .786 & 19 & .753 & 25 & .704 \\
\hline 2 & .830 & 8 & .762 & 14 & .799 & 20 & .816 & 26 & .770 \\
\hline 3 & .773 & 9 & .784 & 15 & .826 & 21 & .758 & 27 & .831 \\
\hline 4 & .783 & 10 & .780 & 16 & .815 & 22 & .736 & 28 & .843 \\
\hline 5 & .779 & 11 & .696 & 17 & .801 & 23 & .753 & 29 & .774 \\
\hline 6 & .774 & 12 & .674 & 18 & .775 & 24 & .816 & 30 & .743 \\
\hline
\end{tabular}

Reliability of Quality of Life Scale:

The validity of the quality of life scale was verified through the application of the tool and its re-application (test-retest), with a difference of two weeks to a sample from outside the sample of the real study of 40 students. Hence, the Pearson correlation coefficient was calculated between the two estimates on the study tool as a whole, where the value ranged between dimensions $(0.62-0.88)$ and the overall $(0.91)$, the reliability coefficient was calculated in the internal consistency method according to the Kronbach Alpha equation, which ranged between dimensions (0.68-0.83) and the overall (89).

\subsubsection{The Second Tool: High-Order Thinking Scale}

The high-order thinking scale was reconstructed for the purposes of the present study, including the most important dimensions of high-order thinking. After reviewing the theoretical literature and previous studies of Al-Jarrah and Obaidat (2011), Al-Khalidi, Al-Kilani, and Al-Awamra (2010), Al-Zahrani (2008), Ghaeb (2011), and Al-Mashharawi (2010), and the scale consisted of (30) paragraphs and includes six dimensions: creative thinking, critical thinking, contemplative thinking, problem solving skills, cognitive thinking, and decision making skills. Each dimension has 5 paragraphs. The student responds in accordance with the gradual five-step Likert ladder: "Always applicable - often applicable - sometimes applicable - rarely applicable - never applicable."

Validity of high-order thinking scale:

The test was presented to eleven arbitrators to judge the suitability of its paragraphs to students, the clarity of its language, the effectiveness of its substitutions, the appropriateness of its number, and the extent to which it represent the high-order thinking skills that were developed to measure them. The correlation coefficients of the high-order reflection scale were calculated for the dimensions of the scale as shown in Table 3. 
Table 3. The correlation coefficients of the high-order thinking level scores with the overall grade of the scale

\begin{tabular}{|c|c|c|c|c|c|c|c|c|c|}
\hline 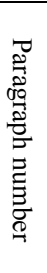 & 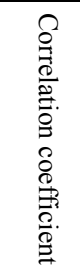 & 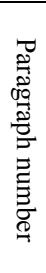 & 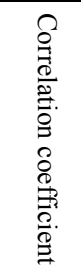 & 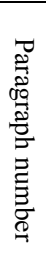 & 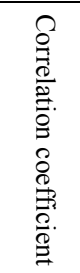 & 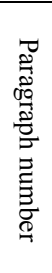 & 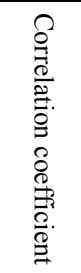 & 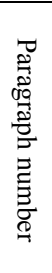 & 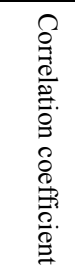 \\
\hline 1 & 0.758 & 7 & 0.825 & 13 & 0.900 & 19 & 0.718 & 25 & 0.762 \\
\hline 2 & 0.684 & 8 & 0.813 & 14 & 0.862 & 20 & 0.794 & 26 & 0.768 \\
\hline 3 & 0.885 & 9 & 0.852 & 15 & 0.795 & 21 & 0.693 & 27 & 0.799 \\
\hline 4 & 0.901 & 10 & 0.748 & 16 & 0.635 & 22 & 0.854 & 28 & 0.901 \\
\hline 5 & 0.870 & 11 & 0.793 & 17 & 0.685 & 23 & 0.854 & 29 & 0.880 \\
\hline 6 & 0.781 & 12 & 0.842 & 18 & 0.748 & 24 & 0.753 & 30 & 0.779 \\
\hline
\end{tabular}

Reliability of the high-order thinking scale:

The reliability of the high-order thinking scale was verified through application and re-application of the tool (test-retest). The application was re-applied by two weeks to a group outside the study sample of (40) students. Therefore, the values of reliability were calculated in the internal consistency method according to the Kronbach alpha equation. The values ranged between (0.71-0.89) between dimensions and overall (0.91)

Debugging key for two scales: In the light of the scale of the response to the quality-of-life scale, and since the graduation of the response scale is five, the answer to all the paragraphs is between (strongly agree, agree, neutral, disagree, and strongly disagree) and correspond to the following grades respectively (5.4.3.2.1) of all paragraphs. The scores on the Quality of Life Scale range from 30 degrees to the lowest score that can be obtained, and 150 degrees are the highest scores that can be obtained on the scale.

In the light of the five-point answer on the paragraphs of the high-order thinking: (Always apply - Apply frequently - Apply occasionally - Rarely applicable - Never applicable). The corresponding grades (5-4-3-2-1) are corresponding to all the paragraphs. The minimum score that the student can get is 30 and the upper grade 150 .

In order to judge the respondents' views on the scales after extracting their mathematical averages, the researcher computed an equation for this by finding the extent of the response on the five-grade response scale, in which the answer to all the paragraphs of the two scales and corresponding to the following grades respectively (5-4-3-2-1) The range of these responses was four and was divided by the number of decisions in which the responses were separated, namely 3 decisions (to a large extent, to a moderate extent, to a low extent) and then the judgment on the resulting value. The points of judgment (the cut point) (1.33) which is the criterion shown in Table 4.

Table 4. Average range of life quality scale rates and high-order thinking scale

\begin{tabular}{ccc}
\hline $\mathrm{N}$ & criterion & \multicolumn{2}{c}{ The average rate that follows } \\
\hline 1 & To a large extent & $(5-3.68)$ \\
2 & To a medium extent & $(3.67-2.34)$ \\
3 & To a low extent & $(1-2.33)$ \\
\hline
\end{tabular}

\subsection{Statistical Analysis}

The researcher entered the results into the statistical packages program (Spss V.17) and then computed the statistical averages and the standard deviations for the grades of the study sample members in order to find the quality of life and high-order thinking among the study sample members.

To examine the relationship between each dimension of quality of life and each high-order thinking skill, the Person Correlation coefficient was used.

In order to examine the gender differences in the two categories (male, female) and the two categories (scientific, human) in the level of quality of life and the level of high-order thinking, independent sample T-test was used to determine the effect of other differences in the level of use. 


\subsection{Study Procedures}

The following procedures were used, based on the scientific research methods applied in the study:

1) Refer to the previous literature, to benefit from some previous studies related to the study, and reference to the books and sources.

2) Preparation of the study tools in the final form. The psychometric characteristics of the study tools were verified in terms of validity and reliability by applying them to a sample of survey from outside the study sample of (40) male and female students.

3) The use of books and official correspondence from the concerned authorities to facilitate the task of applying the study.

4) The researcher distributed the study tools to the sample of the study, consisting of (147) students from Ajloun University College.

5) Transforming the sample responses into raw grades, which were introduced to the computer through the Statistical Package Program (SPSS), to reach the results of the study, to measure the relationship between its variables, and to discuss and extract the recommendations of the study results.

\section{Results of the Study and its Discussion}

The present study aimed at identifying the high-order of thinking and its relation to the quality of life among the students of Ajloun University College. The study questions were answered as follows:

\subsection{Results Relating to the First Question}

What is the level of high-order thinking and quality of life among Ajloun University students?

To answer this question, the arithmetical averages and standard deviations of the responses of the study sample individuals were extracted for the measures of the combined dimensions and on the scale as a whole and as follows:

\section{1) First: The level of high-order thinking among students at Ajloun University College}

Where the statistical averages and the standard deviations of the responses of the sample members of the study were extracted for the combined dimensions and the scale as a whole, as shown in Table 5:

Table 5. The arithmetic averages and the standard deviations of the responses of the sample members of the study on the dimensions of the level of reflection on the level and on the scale as a whole

\begin{tabular}{|c|c|c|c|c|c|}
\hline 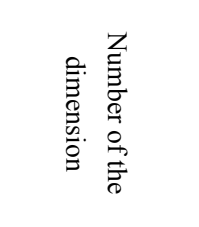 & 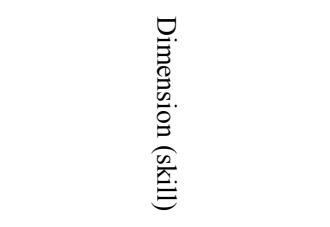 & 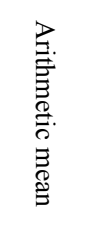 & 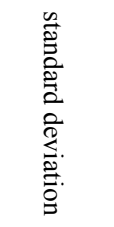 & 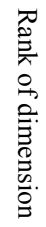 & 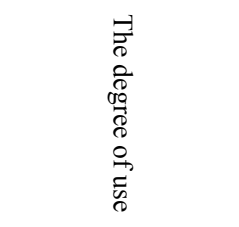 \\
\hline 1 & Creative thinking & 3.2884 & .83588 & 5 & To a medium degree \\
\hline 2 & Critical thinking & 3.3864 & 1.12595 & 1 & To a medium degree \\
\hline 3 & Reflective thinking & 3.3456 & .88319 & 3 & To a medium degree \\
\hline 4 & Problem solving skill & 3.3810 & .96552 & 2 & To a medium degree \\
\hline 5 & Beyond Cognitive Thinking & 3.2490 & .91190 & 6 & To a medium degree \\
\hline 6 & Decision making skill & 3.3388 & .86788 & 4 & To a medium degree \\
\hline Scale as a whole & & 3.3320 & .76991 & & \\
\hline
\end{tabular}

Table 5 shows that the second dimension: critical thinking has obtained the highest response with an average of (38.3) and indicates a medium degree in the high-order thinking and standard deviation of (83.0), followed by the fourth dimension : The skills of solving the problem, and obtained the second degree in terms of possession of the students with an average of (38.3), refers to the degree of medium and standard deviation of $(91,0)$, followed by the third dimension: Reflective thinking with an average of $(34,3)$ indicates a medium degree as well and a standard deviation of (88.0), ranked fourth in the sixth dimension: Decision making skill with an average arithmetic value of (33.3) and a standard deviation of (0.86). It also indicates a middle degree. Followed by the first dimension: creative thinking with an average of (28.3) and a standard deviation of (83.0) it indicates a medium degree too, in the last rank came the fifth dimension: beyond cognitive thinking with a mean of (3.24) and a standard deviation of 
(0.91), it indicates a moderate degree among the study sample as shown in the table. The average response of the sample of the study sample on the scale as a whole was an average of (33.3) which refers to a medium degree and a standard deviation of (76.0).

This result could be due to the moderate degree of high-order thinking skills can be attributed to the fact that members of the study sample have acquired such skills in their schools. In addition, many undergraduate courses can contribute to the development and advancement of such skills as a product of knowledge and learning experiences (Al-Atoum \& Jarrah, 2007). The researcher also finds that these students have passed the high school exam, which is considered to be the forerunner of the mental abilities they possess, and that the students with rates ranging from $68 \%$ to $85 \%$ depending on the disciplines, the researcher believes the logical outcome to suit the capabilities and abilities of students.

The result of this question is inconsistent with the findings of the Ibrahim (2012) study, which found that the students of the faculties of education have a relatively high level of thinking, as well as the results of the study of Nawab and Hussein (2012) which found that the students of the Faculty of Education have high-order thinking in a low degree.

2) Second: The quality of life of students at Ajloun University College:

The statistical averages and the standard deviations of the responses of the sample members of the study were extracted for the combined dimensions and on the scale as a whole, as shown in Table 6.

Table 6. The arithmetical averages and standard deviations of the responses of the study sample members on the dimensions of the quality of life scale and on the scale as a whole

\begin{tabular}{lccccc}
\hline $\mathrm{N}$ & Dimension & Mean & Standard deviation & Rank & Degree of use \\
\hline 1 & Feelings relating the quality of life & 3.3361 & .69597 & 4 & To a medium degree \\
2 & Daily activities & 3.2490 & .83767 & 6 & To a medium degree \\
3 & Different traits in life & 3.2558 & .68638 & 5 & To a medium degree \\
4 & Past experiences & 3.3524 & .95611 & 3 & To a medium degree \\
5 & the ability to move & 3.3673 & .90540 & 2 & To a medium degree \\
6 & Personal beliefs & 3.4204 & .79854 & 1 & To a medium degree \\
\hline \multicolumn{2}{l}{ Scale as a whole } & 3.3299 & .67154 & & \\
\hline
\end{tabular}

Table 6 shows that the sixth dimension: personal beliefs, obtained the highest response with an average of (42.3) and indicates a medium degree in quality of life and standard deviation of (79.0), followed by the fifth dimension: The ability to move, and obtained the second degree in terms of possession of students with an average of (36.3), it also refers to a medium degree and a standard deviation of (90.0), followed by the fourth dimension: Past experiences with an average of (35.3), indicating a medium degree and a standard deviation of (95.0), and in the fourth rank came the first dimension: the feelings of quality of life with an average of (33.3) and a standard deviation of (0.69) and it indicates a moderate degree too, followed by the third dimension: the different characteristics of life with an average of (24.3) and a standard deviation of (68.0), it also indicates a middle degree. The second dimension ranked last: daily activities with an average of (3.25) and a standard deviation of (0.68), and indicates a medium degree in the sample of the study members as shown in the table. The average response of the sample of the study on the scale as a whole was an average of (32.3) indicating a medium degree and a standard deviation of (67.0) this result could be attributed to that the individual's sense of quality of life achieved by the sense of happiness, in addition to the feeling of happiness develops over the past life's where he makes an effort for independence and self-adequacy and improve personal and achieve good relations with others, And accept the self in order to achieve what he aspires to (Al-Karkhi, 2011). The researcher believes that freedom is one means of reaching the quality of life through the freedom to choose, to decide his own destiny and to choose the goals that suit his abilities and tendencies. Or change it or the existence of appropriate academic guidance, we find that achieving this is with a limited limitations in addition to the lack of potential in terms of scientific resources and the use of traditional methods of teaching does not meet the ambition in addition to the academic skills that the student take may not be enough to make him successful in the labor market. In addition, students are surrounded by unemployment, poverty and the inability to satisfy many of the requirements of life, all of which lead to the acquisition of students a degree of quality of life.

The results of the current question are in line with the results of the Adely's (2012) study, which indicated that the average scores of male and female respondents exceed the theoretical average of the scale that reflects a high level 
of quality of life, and also agree with the results of the study of Al-Shanti (2016) Which found that the quality of life was average among individuals working in the Palestinian Ministry of Health in the Gaza Strip, the results of the present study are in contrast to the results of the Naesa's (2012) study, which indicated the low quality of life among university students.

\subsection{Results Relating to the Second Question}

Is there a statistically significant correlation relationship at the level of significance $(\alpha 0.05)$ between high-order thinking and quality of life among Ajloun University students?

To answer this question, the relationship between the dimensions of the high-order thinking and the quality-of-life dimensions was examined by the Pearson test to examine the linear relationship between variables as shown in Table 7.

Table 7. Correlation coefficients to examine the relation between the level of high-order thinking and quality of life by Pearson correlation coefficient

\begin{tabular}{|c|c|c|c|c|c|c|c|c|}
\hline \multirow[b]{2}{*}{$\begin{array}{r}\text { Dimensions of quality } \\
\text { of life }\end{array}$} & \multirow[b]{2}{*}{ 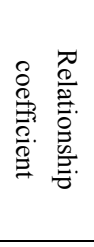 } & \multicolumn{6}{|c|}{ Dimensions of higher-order thinking } & \multirow[b]{2}{*}{ 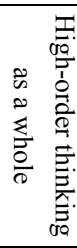 } \\
\hline & & 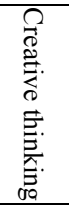 & 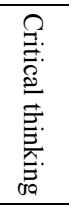 & 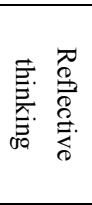 & 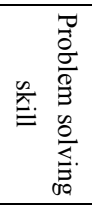 & 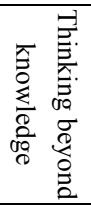 & 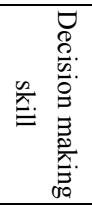 & \\
\hline \multirow{2}{*}{$\begin{array}{l}\text { Feelings related to } \\
\text { quality of life }\end{array}$} & $\mathrm{P}$ & .600 & .717 & .565 & .494 & .542 & .559 & .707 \\
\hline & sig & .000 & .000 & .000 & .000 & .000 & .000 & .000 \\
\hline \multirow[t]{2}{*}{ Daily activities } & $\mathrm{P}$ & .513 & .535 & .507 & .418 & .417 & .378 & .561 \\
\hline & sig & .000 & .000 & .000 & .000 & .000 & .000 & .000 \\
\hline \multirow[t]{2}{*}{ Different traits in life } & $\mathrm{P}$ & .645 & .678 & .562 & .358 & .610 & .612 & .700 \\
\hline & sig & .000 & .000 & .000 & .000 & .000 & .000 & .000 \\
\hline \multirow{4}{*}{$\begin{array}{c}\text { Number of past } \\
\text { experiences } \\
\text { the ability to move }\end{array}$} & $\mathrm{P}$ & .708 & .806 & .740 & .491 & .630 & .624 & .811 \\
\hline & sig & .000 & .000 & .000 & .000 & .000 & .000 & .000 \\
\hline & $\mathrm{P}$ & .687 & .714 & .673 & .499 & .633 & .663 & .781 \\
\hline & sig & .000 & .000 & .000 & .000 & .000 & .000 & .000 \\
\hline \multirow[t]{2}{*}{ Personal beliefs } & $\mathrm{P}$ & .595 & .686 & .595 & .451 & .621 & .624 & .723 \\
\hline & sig & .000 & .000 & .000 & .000 & .000 & .000 & .000 \\
\hline \multirow{2}{*}{$\begin{array}{c}\text { Quality of life as a } \\
\text { whole }\end{array}$} & $\mathrm{P}$ & .761 & .838 & .743 & .551 & 699 & .700 & .869 \\
\hline & sig & .000 & .000 & .000 & .000 & .000 & .000 & .000 \\
\hline
\end{tabular}

* Statistical significant at the level of significance $(\alpha=0.05)$.

Table 7 shows that there is a statistically significant correlation at the level of significance $(\alpha=0.05)$ between the quality of life, the daily activities, the different characteristics of life, the number of past experiences, the ability to move, the personal beliefs and the overall score of the quality of life standard and all high-order thinking skills: creative thinking, critical thinking, contemplative thinking, problem solving skills, cognitive thinking, decision-making skills and the overall degree of high-order thinking.

The reason is that students with high-order thinking have the ability to cope with problems and solve them. They are the most satisfied with life and the most satisfaction, happiness, optimism and positive outlook towards life. This is only an expression of what the individual thinks in a way that leads to happiness and a sense of quality of life, The high-order thinking of the individual leads to the love of learning and exploration and seeking to know what is new and thus lead to the psychological and social consensus and reflected positively on the individual's perception of quality of life, the proper perception of the reality of living increases the ability of the individual to face the problems, also reflected positively on the individual's awareness of the quality of life.

Selgman et al. (2005) point out that optimism is a fundamental dimension in a personality that thinks positively. Optimism is linked to positive expectations that are not related to a given situation. It identifies the good way to achieve goals. Carr (2004) points out that the high degree of thinking and the quality of the individual is and that the nature of the human being seeks to be a positive model does not give excuses to others and have the courage to allow them to assume their responsibilities without hesitation, adding that high-order thinking is a source of real happiness, it help the individual on positive interaction with others and enables him to set himself a goal and 
prepare him to face difficulties is a way to stimulate motivation.

The result of this study is consistent with the results of the Shek's (1993) study which found a positive relationship between the quality of life and the psychological happiness of university students. The result of this study is consistent with the results of the Najjar and Al-Ra'eef's (2015) study, which indicated a relationship between the positive thinking and the quality of life, as well as the results of the Shanti study (2016), which found the positive relationship between transformational leadership and quality of life.

\subsection{Results Relating to the Third Question}

Are there statistically significant differences at the level of $(\alpha=0.05)$ in the level of high-order thinking and quality of life among Ajloun University students due to the variable (gender and academic specialization)?

To answer this question, a T-test was used for the independent samples of both gender variables and academic specialization as follows:

1) First: Differences in quality of life and high-order thinking among students at Ajloun University College, which are attributed to gender variable:

T-test was used for the independent gender variable. Table 8 shows the arithmetical averages and standard deviations of the differences between males and females and the results of the T-test for independent samples in the quality of life and high-order thinking:

Table 8. Test (T) for independent samples to examine differences in quality of life and high-order thinking among students of Ajloun University College, which is due to gender variable

\begin{tabular}{cccccccc}
\hline Source & Students & $\mathrm{N}$ & Mean & Standard deviation & T value & Df & Sig \\
\hline \multirow{2}{*}{ Quality of life } & Female & 79 & 3.0046 & .51079 & $-7.409-$ & 145 & \multirow{2}{*}{0.000} \\
& Male & 68 & 3.7079 & .63961 & & & \\
\multirow{2}{*}{ Higher-order thinking } & Female & 79 & 2.9642 & .62834 & $-7.266-$ & 145 & \multirow{2}{*}{0.000} \\
& Male & 68 & 3.7593 & .69803 & & \\
\hline
\end{tabular}

Table 8 shows that there are statistically significant differences at the level of $(\alpha=0.05)$ in the quality of life level due to the gender variable where the value of test (7.409) is statistically significant as shown by the statistical significance. Male superiority over females in quality of life is clear.

The result of differences in the quality of life in males can be attributed to the fact that male cognition may be reflected in their interpretation of the surrounding life. On the one hand, differences in biological, psychological and social characteristics may have an impact on these differences; the prevailing social situation imposed on females limits the perception of happiness and optimism and negatively affects their quality of life. The results of this study are consistent with the results of Najjar and Al-Ra'eef's (2015) study, which indicated differences in the level of thinking and quality of life and in favor of males. This result contradicts the study of Naissa (2012), which indicated no statistically significant differences in quality of life between males and females.

Table 8 shows that there are statistically significant differences at the level of $(\alpha=0.05)$ in the level of high-order thinking due to the gender variable. The value of the test (7.266) is statistically significant as shown by the statistical significance, the result is attributed to the patterns of socialization and prevailing environmental norms that give care and attention to males more than females, and males have more life experiences in different areas of life. On the other hand, the degree of freedom granted to males greater than the degree which are subject to many restrictions and which reflect their degree of thinking.

This result is consistent with the results of Al-Najjar and Al-Ra'eef's (2015) study, which indicated that there were differences in the positive thinking scale due to gender and male interests. The result of this question also differs with the results of the study of Nawab and Hussein (2012) females have high-order thinking higher than males, and college students have higher-order thinking than science colleges, and first-year students have higher-order thinking than other years.

2) Second: Differences in the quality of life and higher- order thinking among the students of Ajloun University College, which are attributed to the variable of academic specialization

Where the $\mathrm{T}$ test was used for independent samples according to academic specialization variable, the following table shows the statistical averages and standard deviations of the differences between the students in the scientific and human faculties and the results of the $\mathrm{T}$ test for independent samples in the quality of life and high-order 
thinking.

Table 9. T-test for independent samples to examine differences in quality of life and high-order thinking among students of Ajloun University College, due to the variable of academic specialization

\begin{tabular}{lccccccc}
\hline Source & Students & $\mathrm{N}$ & Mean & Standard deviation & T value & Df & Sig \\
\hline \multirow{2}{*}{ Quality of life } & Huminatarian & 88 & 2.9674 & .49452 & \multirow{2}{*}{$-10.624-$} & 145 & .000 \\
& Scientific & 59 & 3.8707 & .52105 & & & \\
\multirow{2}{*}{ Higher-order thinking } & Huminatarian & 88 & 2.9145 & .59697 & \multirow{2}{*}{$10.705-$} & \multirow{2}{*}{145} & .000 \\
& Scientific & 59 & 3.9546 & .54669 & & \\
\hline
\end{tabular}

Table 9 shows that there are statistically significant differences at the level of $(\alpha=0.05)$ in the quality of life level due to the specialization variable where the value of the $t$ test (10.624) is a statistically significant value as shown by the statistical significance. Students from the scientific colleges have surpassed students from the humanitarian faculties in quality of life.

Differences in the quality of life in favor of males in the scientific specialization can be attributed to the optimism of the student in accordance with the prevailing social standard, which considers the scientific disciplines in a great and valuable way, and this is reflected in the self-concept of the student in this scientific section on the one hand, and on the other hand, job opportunities for computer and mathematics majors in Jordan is available, which is reflected on the psychological side of the student and therefore reflected on the quality of life, the results of the current question are consistent with the results of Al-Adli study (2006), which indicated that there were statistically significant differences between the average performance of the students on the quality of life standard according to the specialization. It was determined by the differences between the average score of students in social studies and average performance of the other disciplines covered by the research, Naesa's (2012) study, which found differences due to the combined effect of the three demographic variables on the quality of life.

Table 9 shows that there are statistically significant differences at the level of $(\alpha=0.05)$ in the level of high-order thinking attributed to the variable of academic specialization. The value of the t-test was (10.705) which is a statistically significant value as shown by statistical significance. Mathematical means of the students in the faculties of higher education are more likely to excel in higher-order thinking. The result is due to the mental abilities they possess. This is reflected in the high school scores they received, which enabled them to enter the academic colleges also for their academic motivation, reflecting on their perseverance and try to think in a contemplative and creative way to fit their image of themselves and society's perception of them.

The result of this question differs with the results of the study of Ibrahim (2012) which found that there are statistically significant differences in gender, specialization and stage in the level of high-order thinking in favor of (females, human specialization and the first stage).

\subsection{Suggestions of the Study}

In view of the above, the following suggestions were presented:

1) Conduct further research and studies on the relationship between quality of life and other variables such as self-efficacy, self-learning, and other variables.

2) The curriculum should include broader thinking skills and work to train students on skills that raise their high-order thinking skills because they have a close relationship to quality of life.

3) Conduct workshops and pilot studies to improve students' perception of level, quality and satisfaction.

4) Universities must include in their job cadres educational guides to guide students in various aspects reflected positively on the skills of thinking and then on the quality of their lives.

\section{References}

Abdul Wahid, S. (2012). The effectiveness of teaching with high-order thinking skills in the achievement of the science of revival for fourth grade students, the adequacy of cognitive representation and the development of critical thinking among fourth grade students (Master Thesis, University of Baghdad, Iraq, Baghdad).

Abu Halawa, M. (2010). The Quality of Life Concept and Dimensions. 7th Scientific Conference of the Faculty of Education, Kafr El-Sheikh University, Quality of Life as an Investment for Educational and Psychological Sciences. 
Abu Hatab, F., \& Othman, S. (1988). Thinking: Psychological Study (3rd ed.). The Anglo Egyptian Library, Cairo, Egypt.

Adely, K. (2006). The extent to which the students of the Faculty of Education in Al-Rustaq have a sense of quality of life, and its relation to some variables. Proceedings of the Symposium on Psychology and Quality of Life (pp. 37-47), Sultan Qaboos University, Sultanate of Oman.

Al-Khaimi, M. (2008). The effectiveness of indirect counseling in the development of some positive aspects of personality in a sample of University students (Unpublished $\mathrm{PhD}$ thesis). Faculty of Education, Sohag University.

Al-Mashharawi, B. (2010). The cognitive impulse and the classroom environment and their relation to the contemplative thinking of high school students in Gaza City (Unpublished master thesis). Al-Azhar University, Gaza, Palestine.

Burtson, P. L., \& Stichler, J. F. (2010). Nursing work environment and nurse caring: relationship among motivational factors. Journal of Advanced Nursing, 66(8), 1819-1831. https://doi.org/10.1111/j.1365-2648.2010.05336.x

Carr, A. (2004). Positive psychology: The science of happiness and human strength. Hove and New York: Braner-Rutledge.

El-Rab, S. G. (2008). Quality of Career in Egyptian Business Organizations. Cairo, Egypt.

Ghaeb, N. (2011). Problem Solving Strategies for Preparatory Students in Khanaqin District. Diyala Journal, College of Education, Baghdad, Iraq.

Goode, D. (1990). Thinking about and discussing quality of life, In R. Schalock, \& M. J. Bogale (Eds.), Quality of life: Perspectives and issues (pp. 41-58). Washington, DC: American Association of Mental Retardation

Hindawi, M. (2012). Social support and its relationship to the level of satisfaction with the quality of life of the physically disabled in Gaza Governorate (Master Thesis, Al Azhar university, Gaza).

Ibrahim, H. (2012). Habits of Reason and Higher-Order Thinking and their Relationship to Self Effectiveness among Students of the Faculty of Education, University of Baghdad (Master thesis, Baghdad, Iraq).

Jarrah, A., \& Obaidat, A. (2011). The level of thinking beyond the knowledge of a sample of Yarmouk University students in the light of some variables. Jordanian Journal of Educational Sciences, 7(2).

Jawdat, S. (2003). Teaching Thinking Skills with hundreds of applied examples (1st ed.). Amman, Jordan: Dar Al Shorouk Publishing and Distribution.

Karkhi, K. (2011). Quality of Life of Educational Counselors and their Relation to Emotional Intelligence (Unpublished master thesis). Faculty of Basic Education, Diyala University.

Khalidi, J., Al Kilani, A., \& Al Awamra, M. (2010). The degree of practice of Islamic education teachers and their teachers of higher thinking skills from the point of view of secondary students in Jordan. Al-Quds Open University Journal for Research and Studies, 23(1).

Naesa, R. (2012). Quality of Life of Damascus and Teshreen University Students. Damascus University Journal, Faculty of Education, Damascus University, 28(1).

Najjar, Y., \& Al-Tallah (2015). Positive Thinking and its Relationship to the Quality of Life of Employees of NGOs in Gaza Governorate. Al-Najah University Journal of Humanities, 29(2).

Newman, F. (1991). Promoting High Order Thinking Skils In Social Studies: Overview of A study of 16 Higher School Department. Theory and Research in Social Education, 19(4), 324-340 https://doi.org/10.1080/00933104.1991.10505645

Northouse, P. G. (2013). Leadership theory and practice (6th ed.). Thousand Oaks, CA: Sage publication.

Nuwab, N., \& Hussein, M. (2012). Habits of Reason and High-Order Thinking and their Relation to the Self Effectiveness of Students of Faculties of Education (Unpublished master thesis). Faculty of Education Ibn Al Haytham, University of Baghdad, Iraq.

Okasha, F., \& Abdel Aziz, S. (2010). The relationship between the quality of psychological life and linguistic disability. A research presented to the scientific conference of the Faculty of Education, Kafr El-Sheikh University entitled "Quality of life as an investment of psychological and educational sciences".

Qatami, Y., Qatami, N., \& Hamdi, N. (2010). Teaching Design (1st ed.). United Arab Marketing \& Supply Co., 
Amman, Jordan.

Ryff, C, Love, G., Urry, H., Muller, D., Rosen-Kranz, M., Friedman, E., ... Singer, B. (2006). Psychological Well-Being and Ill-Being: Do They Have Distinct or Mirrored Biological Correlates? Psychotherapy Psychosomatics, 75, 85-95.

Selgman, M. E. P., Steen, T. A., Park, N., \& Peterson, C. (2005). Positive psychology progress: Empirical validation of intervention. American Psychologist, 40 60(5), https://doi.org/10.1037/0003-066X.60.5.410

Shanti, M. (2016). The Effect of Transformational Leadership Practices on Quality of Career Life: An Empirical Study on Palestinian Health. University of Jordan Journal, University of Jordan, 12(1).

Sheikhi, M. (2014). The nature of life and its relation to the quality of life, A field study in the light of some variables (Unpublished master thesis). University of Abu Bakr Belqayd, Algeria.

Shek, D. (1993). The Chinese purpose in life test and Psychological well-being in Chinese college students. International Forum for Logotherapy, 16(11), 35-42.

Shuraidah, M., \& Beshara, M. (2010). Complex Thinking and its Relation to Some Variables (A Field Study of the Students of Al-Hussein Bin Talal University). Damascus University Journal, 26(3).

Stewart-Brown, S. (2000). Parenting, well-being, health and disease. In A. Buchanan, \& B. Hudsen (Eds.), Promoting Children's Emotional Well-being. Oxford: Oxford University press

Taylor, H., \& Bogdan, R. (1990). Quality of life and the individual perspective. In R. L. Schalock, \& M. Begab (Ed.), Quality of life perspectives and issues (pp. 27-40). Washington, DC: American Association.

Zahrani, S. (2008). Professional preference and decision-making among a sample of students of vocational colleges in Jeddah (Unpublished master thesis). Faculty of Education, Umm Al-Qura University, Saudi Arabia.

\section{Copyrights}

Copyright for this article is retained by the author(s), with first publication rights granted to the journal.

This is an open-access article distributed under the terms and conditions of the Creative Commons Attribution license (http://creativecommons.org/licenses/by/4.0/). 